\title{
Virtual reality and consumer behavior: constraints, negotiation, negotiation- efficacy, and participation in virtual golf
}
Authors' contribution:
A) conception and design of the study
B) acquisition of data
C) analysis and interpretation of data
D) manuscript preparation
E) obtaining funding

\author{
T. Christopher Greenwell2A-D \\ ${ }^{1}$ Kyung Hee University, Korea \\ ${ }^{2}$ University of Louisville, USA \\ ${ }^{3}$ Indiana University-Bloomington, USA
}

Chulhwan Choi ${ }^{1 \mathrm{~A}-\mathrm{D}}$, Sin-Wook Yoo ${ }^{2 \mathrm{~A}-\mathrm{D}}$, Jin Park ${ }^{3 \mathrm{~A}-\mathrm{D}}$,

ABSTRACT

The emergence of virtual sports shows promises in encouraging participation among those who may be constrained from participating in traditional recreational sports (Choi et al., 2019). To maximize virtual sports' potential in increasing sports participation, this study aimed to investigate the relationships between constraints, negotiation, negotiation-efficacy, and participation. Results from virtual golf participants found that, as predicted, (a) constraints had a negative direct influence on participation, (b) negotiation-efficacy had a negative direct influence on constraints, (c) negotiationefficacy had a positive direct influence on negotiation, and negotiation had a positively direct influence on participation. The findings of this study indicated that reduced constraints did not result in increasing virtual golf consumers' participation because negotiation did not play a significant role in their decision to participate. Thus, the current study provides a comprehensive understanding of interrelationships among leisure participation, constraints, and negotiation, particularly extending to the context of virtual golf.

KEYWORDS golf, virtual reality, leisure, consumer behavior

\section{Introduction}

Advanced technology has altered and benefitted people's lifestyle. Virtual reality is one of the cutting-edge technologies allowing individuals to experience a realistic virtual environment (Lee, Cheon, Judge, Shin, \& Kim, 2012) as it turns imagination into reality within computer-based environment. In the sport industry, virtual reality has not only brought about dramatic changes in consumption patterns, but also has generated new types of sports (Young \& Pederson, 2010).

Indoor virtual golf, also called "screen golf" has experienced outstanding growth in the Republic of Korea (Jung, Park, Kang, Lee, \& Hahn, 2010; Kim, Seo, Kim, \& Chang, 2014; Lee, Chung, \& Lee, 2013). With the virtual reality created by high-definition golf simulators (Jung et al., 2010), the popularity of this emerging sport-related business has threatened that of outdoor field golf. Participation in the sport is especially strong in East Asia. It is estimated that 200,000 individuals per day play virtual golf in the Republic of Korea, and both Japan and China have seen strong growth in the market (Kerr-Dineen, 2018). In the United States, The National Golf 
Foundation (NGF) estimates there are four million virtual golf participants, and that half of them have never played outdoor golf (Schupak, 2018).

In a recent study, Choi, Greenwell, Hums, and Hambrick (2019) found virtual golf decreased levels of consumers' perceived constraints that have long been considered significant in outdoor golf (i.e., cost, weather, time, and skill/confidence), making it easier for individuals to participate. This study seeks to extend the prior work by

a) examining the extent to which constraints predict virtual golf participation and

b) investigating the relationships between constraints, negotiation, negotiation-efficacy, and participation.

Findings from this study provide a theoretical groundwork for better understanding the complex psychological dimensions of virtual sport consumers and suggest a concrete future direction for practitioners in technologybased sport industries.

\section{Literature review}

\section{Leisure Constraints}

Leisure constraints are defined as factors that may prevent or reduce participation in leisure activities (Jackson, 1988). Since it also referred to as inhibitors (Um \& Crompton, 1992) or barriers (Smith, 1987), leisure constraints may not only limit participation but also hinder acquisition of leisure preferences (Crawford \& Godbey, 1987) and leisure participation intentions (Iso-Ahola \& Mannell, 1985). Crawford and Godbey (1987) found three types of constraints:

a) Intrapersonal barriers (e.g., stress, depression, and anxiety),

b) Interpersonal barriers (e.g., relationship with a spouse, children, or friends), and

c) Structural barriers (e.g., financial resources, lifestyle, season, climate, and work time).

Specific to golf, a variety of constraints such as skill, social, time, and cost have been found to have a negative effect on participation (Jun \& Kyle, 2011; Lyu \& Lee, 2018). Golfers are likely to choose participation opportunities where they are likely to experience fewer constraints. These constraints may differ according to context, as Choi et al. (2019) found both virtual and outdoor golfers experienced the same level of social and health constraints, while virtual golfers were less constrained by cost, weather, time, and skill/confidence. Given constraints are conceptualized as limiting participation, the first hypothesis posits that higher levels of these six constraints will result in lower virtual golf participation.

H1: Constraints have a negative direct influence on virtual golf participation.

\section{Leisure Constraint Negotiation}

Whereas existing research (Crawford \& Godbey, 1987; Crawford, Jackson, \& Godbey, 1991) defined constraints on leisure participation as insurmountable barriers, Jackson, Crawford, and Godbey (1993) emphasized the "negotiation" process in an individual's participation decision. Jackson et al. (1993) noted (a) when encountering a constraint, people might negotiate the constraint in various ways, (b) the outcome was not necessarily nonparticipation, and (c) participation through a successful negotiation process could be considerably different from participation in the absence of constraints in terms of engagement level, frequency of participation, etc. In the same vein, Scott (1991) described how successful negotiation would be a prerequisite process of leisure involvement, indicating leisure constraints might bring about modified participation rather than nonparticipation.

Until recently, leisure constraints have been discussed as a negotiable factor in individuals' decision-making process (Alexandris \& Carroll, 1997; Hawkins, Peng, Hsieh, \& Eklund, 1999; Jackson \& Dunn, 1991; Jackson \& Rucks, 1993), through applying diverse concepts to leisure negotiation process, such as social identities (e.g., 
parent, friend, and others), identity conflict, and identity facilitation (Jun \& Kyle, 2011). The findings were consistent with the previous concept of negotiation (Jackson et al., 1993) that participation was dependent on the negotiation process, as they emphasized the importance of negotiation on leisure constraints research. Hubbard and Mannell (2001) proposed that individuals encountering constraints would be both inhibited from participating in the activity and prompted to negotiate the constraint. White (2008) confirmed this relationship finding constraints were positively correlated with negotiation. Negotiation, in turn, increased participation. Therefore, the second and third hypotheses state:

$\mathrm{H} 2$ : Constraints have a positive direct influence on negotiation in virtual golf.

H3: Negotiation has a positive direct influence on virtual golf participation.

\section{Negotiation-Efficacy}

While previous empirical studies (Hubbard \& Mannell, 2001; Jackson et al., 1993; Jun \& Kyle, 2011) have identified and demonstrated negotiation as one of the significant components in leisure studies, there has been a growing need to further examine the notion of negotiation on a theoretical basis (Henderson, Bedini, Hecht, \& Schuler, 1995; Hubbard \& Mannell, 2001). A number of researchers have suggested self-efficacy might play a significant role in an individual's negotiation process and might provide more rationales into the existing leisure constraints model (Henderson et al., 1995; Hubbard \& Mannell, 2001; Loucks-Atkinson \& Mannell, 2007).

Loucks-Atkinson and Mannell (2007) conducted the first study extending the existing leisure constraints framework by applying self-efficacy into the context of leisure constraints. Self-efficacy directly affects an individual's cognitive process, and it leads to motivational behavior for certain expected outcomes and goals. To achieve such goals, an individual tends to make efforts even when facing challenges. Loucks-Atkinson and Mannell (2007) proposed a new concept, "negotiation-efficacy," based upon the concept of self-efficacy. Negotiation-efficacy was defined as "people's confidence in their ability to successfully use negotiation strategies to overcome constraints" (Loucks-Atkinson \& Mannell, 2007, p.20), and Loucks-Atkinson and Mannell (2007) asserted negotiation-efficacy works as a mediator, which indirectly influences participation through motivations, constraints, and negotiation. As predicted, higher negotiation-efficacy led to higher motivations, negotiation efforts, and lower perception of constraints, which eventually have indirect positive influences on participation (Ridinger, Funk, Jordan, \& Kaplanidou, 2012; White, 2008). This leads to the fourth and fifth hypotheses:

H4: Negotiation-efficacy has a positive direct influence on negotiation in virtual golf.

H5: Negotiation-efficacy has a negative direct influence on constraints in virtual golf.

\section{Methods}

\section{Data Collection Procedure}

To meet the purpose of this study, the data collection was implemented from people over 20 years old in the Republic of Korea with experience playing virtual golf. Based on the purposive sampling technique, two virtual golf centers in the Republic of Korea were selected. Customers in the virtual golf centers voluntarily participated in an online-based survey pre-created on Qualtrics.com (online survey platform). Specifically, a Uniform Resource Locator (URL) connecting to the Qualtrics.com was sent to all voluntary survey respondents via their mobile phones. Through the URL, participants accessed and completed survey questionnaires of this study. A total of 600 questionnaires were distributed, and after excluding 21 incomplete surveys, 212 out of 233 returned questionnaires (38.8\% response rate) were utilized in this study. Data collection procedure lasted for three weeks on January 2017. 


\section{Measures}

The study utilized (a) leisure constraints, (b) negotiation, (c) negotiation-efficacy, and (d) participation to investigate the relationships among the variables. Each item anchored in 7-point Likert scale ranging from 1 (Strongly Disagree) to 7 (Strongly Agree).

Leisure constraints scale. Based on the purpose of this study, the current study modified the leisure constraints scale which were utilized from a research of Jun and Kyle (2011) and developed from a study of Choi (2016). The leisure constraints were measured with 4 factors including 12 items: (a) social (3 items; e.g., "my family/friends have different interests than virtual golf"), (b) skill/confidence (3 items; e.g., "I'm too inexperienced to play virtual golf"), (c) cost (3 items; e.g., "I don't have enough money to play virtual golf"), and (d) time ( 3 items; e.g., "I have no time to play virtual golf").

Negotiation scale. This study applied the negotiation scale utilized from a study of Jun and Kyle (2011). This instrument comprised 4 factors with 12 items: (a) social ( 3 items; e.g., "I try to persuade close people to play virtual golf"), (b) skill/confidence (3 items; e.g., "I try to play more virtual golf to get better"), (c) cost (3 items; e.g., "I buy inexpensive equipment for virtual golf"), and (d) time ( 3 items; e.g., "I try to play virtual golf whenever possible").

Negotiation-efficacy. The survey also measured negotiation-efficacy of virtual golf consumers. Following the standard of White (2008), respondents were asked to rate their confidence in the successful use of specific negotiation resources to cope with leisure constraints ( 3 items; e.g., "I enjoy overcoming obstacles to virtual golf participation").

Participation. Participation level was measured through a question asking the participation frequency playing virtual golf in a month prior to the survey (i.e., How many times did you play virtual golf in a month recently?)

\section{Validity and Reliability}

Exploratory factor analysis (EFA) using a principal component analysis (PCA) with orthogonal rotation (Varimax) was performed to determine the underlying factor structure for virtual golf consumers' leisure constraints and negotiation. To decide on how many components to retain, three criteria were applied: (a) Eigenvalue greater than 1.0, (b) parallel analysis, and (c) the amount of total variance explained by factors (greater than 70\%; Stevens, 2009). The negotiation-efficacy and participation consisting of one single factor each were excluded from this analysis. Also, Cronbach's alphas were utilized to confirm the internal reliability consistency. Lastly, to test a hypothesized measurement model of this study, Confirmatory factor analysis was performed based on comparative fit index (CFI), Tucker-Lewis index (TLI), root mean square residual (RMR), and root mean square error of approximation (RMSEA).

\section{Data Analysis}

Structural equation modeling (SEM) using the Statistical Package for the Social Sciences (SPSS) and analysis of a moment structures (AMOS) 22 was conducted to test measurement model and the structural model in the current research investigating consumer behaviors of virtual golf (i.e., leisure constraints, negotiation, negotiation-efficacy, and participation).

\section{Results}

\section{Frequency Distribution of Variables}

The subjects consisted of 189 (89.2\%) males and 23 (10.8\%) females, which closely reflects the virtual golf population in the Republic of Korea found in previous research where nearly $70 \%$ of total participants were 
male (Han, Baek, Lee, \& Huh, 2014; Lee et al., 2012). In terms of age, 75.9\% $(n=161)$ of the sample was between the ages of 30 and 39 years old. In regard to marital status, 96 (45.3\%) were single, $116(54.7 \%)$ were married. In relation to participants' highest level of education completed, a majority of survey participants had a bachelor's degree $(n=137,64.6 \%)$, followed by a master's degree $(n=53,25.0 \%)$, a high school degree $(n$ $=6,2.8 \%)$, and a doctorate degree $(\mathrm{n}=16,7.5 \%)$. In regard to average scores in virtual golf, participants reporting between 83 and 97 comprised $36.3 \%$ of the total sample $(n=77)$, followed by greater than 97 , less than $83(\mathrm{n}=48,22.6 \%)$, and "I don't know"( $\mathrm{n}=22,10.4 \%)$.

\section{Exploratory Factor Analysis}

Leisure constraints. The Kaiser Meyer-Olkin (KMO) measure verified the sample adequacy for the analysis $(\mathrm{KMO}=.74)$, exceeding the criteria $\left(.70\right.$; Field, 2009). Bartlett's test of sphericity $\left(\chi^{2}=1502.77, d f=66, p<\right.$ .001 ) was statistically significant. The extracted communalities were generated to reflect the proportion of variance explained by the retained factors, and the values ranged from .71 to .92 , exceeding the criteria (.40) (Stevens, 2009). Based on the factor loading of .50 as a cutoff point, 4 factors with 12 items in leisure constraints were retained (Table 1).

Table 1. Factor structure matrix for leisure constraints in virtual golf

\begin{tabular}{lccccc}
\hline Constraints items & $\mathbf{1}$ & $\mathbf{2}$ & $\mathbf{3}$ & $\mathbf{4}$ & $\boldsymbol{h}^{\mathbf{2}}$ \\
\hline Skill/Confidence1 & .92 & & & & .88 \\
Skill/Confidence2 & .91 & & & & .85 \\
Skill/Confidence3 & .81 & & & & .71 \\
Cost 1 & & .89 & & & .89 \\
Cost 2 & & .89 & & & .89 \\
Cost 3 & .82 & & & .69 \\
Time1 & & .87 & & .81 \\
Time 2 & & & .87 & & .79 \\
Time 3 & & & .75 & & .60 \\
Social 1 & & & & .89 & .80 \\
Social 2 & & & & .83 & .74 \\
Social 3 & & & & .71 & .59 \\
\hline Eigenvalues & 34.67 & 1.84 & 1.64 & 1.62 & \\
\% of Variance & .89 & .85 & .81 & .89 & \\
Cronbach's alphas & & & .83 & 13.47 & \\
\hline
\end{tabular}

Note. $1=$ Skill/Confidence, $2=$ Cost, $3=$ Time, $4=$ Social; $h^{2}=$ communalities.

Source: own study.

Negotiation. The KMO measure verified the sample adequacy for the analysis $(\mathrm{KMO}=.79)$, exceeding the criteria (.70; Field, 2009). Bartlett's test of sphericity $\left(\chi^{2}=1448.52, d f=66, p<.001\right)$ was statistically significant. The extracted communalities were generated to reflect the proportion of variance explained by the retained factors, and the values ranged from .63 to .93 , exceeding the criteria (.40; Stevens, 2009). Based on the factor loading of .50 as a cutoff point, 4 factors with 12 items in negotiation were retained (Table 2).

\section{Scale Reliability}

Cronbach's alphas reported acceptable internal consistency for reliability (greater than .70 ; Nunnally \& Bernstein, 1994): Constraints (Skill/Confidence, $\alpha=.89$; Cost, $\alpha=.85$; Time, $\alpha=.81$; Social, $\alpha=.89$ ), Negotiation (Time, $\alpha=.90$; Skill/Confidence, $\alpha=.85$; Social, $\alpha=.84$; Cost,$\alpha=.75$ ), and Negotiation-efficacy $(\alpha=.86)$. 
Table 2. Factor structure matrix for negotiation in virtual golf

\begin{tabular}{lccccc}
\hline Negotiation items & $\mathbf{1}$ & $\mathbf{2}$ & $\mathbf{3}$ & $\mathbf{4}$ & $\boldsymbol{h}^{\mathbf{2}}$ \\
\hline Time1 & .88 & & & & .83 \\
Time2 & .88 & & & & .83 \\
Time3 & .88 & & & & .83 \\
Skill/Confidence 1 & & .90 & & & .85 \\
Skill/Confidence 2 & & .87 & & & .79 \\
Skill/Confidence 3 & & .71 & & & .72 \\
Social 1 & & .93 & & .89 \\
Social 2 & & .92 & & .87 \\
Social 3 & & .63 & & .65 \\
Cost 1 & & & & .84 & .76 \\
Cost 2 & & & & .78 & .76 \\
Cost 3 & & & .63 & .66 \\
\hline Eigenvalues & 4.75 & 2.02 & 1.63 & 1.03 & \\
\% of Variance & 39.55 & 16.86 & 13.61 & 8.61 & \\
Cronbach's alphas & .90 & .85 & .84 & .75 & \\
\hline
\end{tabular}

Note. 1 = Time, 2 = Skill/Confidence, $3=$ Social, $4=$ Cost; $h^{2}=$ communalities.

Source: own study.

\section{Structural Equation Model}

Measurement model. The measurement model using a confirmatory factor analysis (CFA) showed an acceptable model fit to the data $\left(\chi^{2}=722.37, d f=34, p<0.01, \mathrm{NFI}=.82, \mathrm{CFI}=.89\right.$, RMSEA $\left.=.07\right)$. Given that values of NFI above .80 (Hooper, Coughlan, \& Mullen, 2008), CFI above .80 (Hu \& Bentler, 1998), and RMSEA of .08 or less (Browne \& Cudeck, 1993) were considered adequate, the measurement model to the data was acceptable.

Structural model. Leisure constraints, negotiation, and negotiation-efficacy were exogenous variables (independent variable), and participation in virtual golf was an endogenous variable (dependent variable). The structure model on SEM revealed an acceptable model fit to the data $\left(\chi^{2}=724.14, d f=34, p<0.01, \mathrm{NFI}=.82\right.$, $\mathrm{CFI}=.89$, RMSEA $=.07$ ), following the statistical standard that values of NFI above .80 (Hooper et al., 2008), CFI above $.80(\mathrm{Hu} \&$ Bentler, 1998) and RMSEA of .08 or less (Browne \& Cudeck, 1993) were considered adequate. Four standardized path coefficients were statistically significant: (a) Constraints to participation $(\beta=$ -.42), (b) negotiation to participation $(\beta=.32)$, (c) negotiation-efficacy to negotiation $(\beta=.60)$, and (d) negotiation-efficacy to constraints $(\beta=-.37)$. The standardized path coefficient was not statistically significant for constraints to negotiation $(\beta=.17)$ (Figure 1).

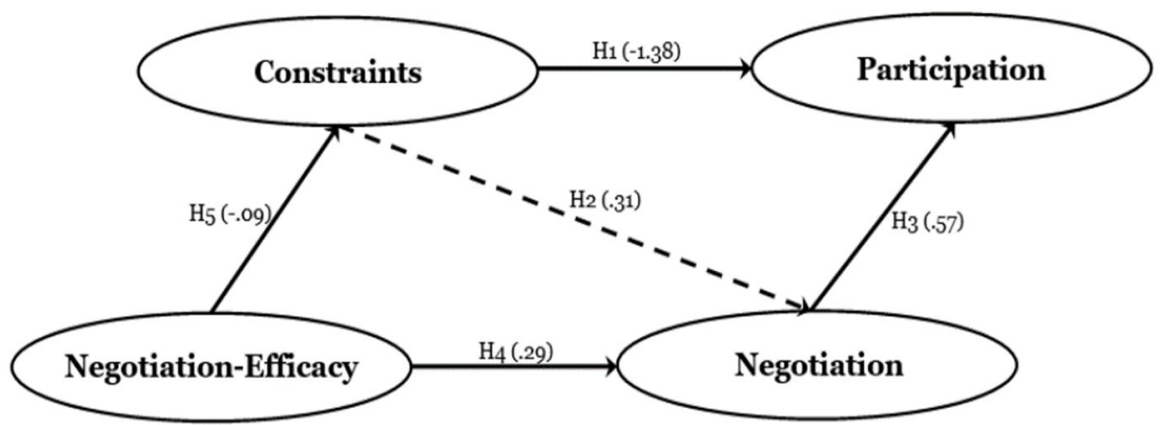

Figure 1. Structural model of constraints, negotiation, negotiation-efficacy, and participation in virtual golf Source: own study. 


\section{Discussion}

Indoor virtual golf (i.e., screen golf) became one of the popular sport entertainment options in the Republic of Korea by satisfying demands of consumers who have experienced restrictions (e.g., weather, cost, and time) in enjoying outdoor golf. The trend has shown the potential of virtual golf for becoming an alternative to outdoor golf as well as an autonomous sport genre. Furthermore, previous research revealed new technology contributes in reducing some of the constraints associated with outdoor golf (Choi et al., 2019). However, no additional efforts have been made to examine the positive influence of those reduced constraints with negotiation process on virtual golf consumers' participation. Therefore, this study examined the extent to which constraints predict virtual golf participation and the role of negotiation in the relationship between constraints and participation.

In regard to the first research question (RQ1: Are the constraints of social, skill/confidence, cost, and time significant predictors of participation in virtual golf?), results showed skill/confidence and time significantly accounted for participation. Contrary to the findings from a previous study (White, 2008), it was found both an intrapersonal constraint (skill/confidence) and a structural constraint (time) were the most significant constraints for participating in virtual golf. In addition, this result was not consistent with Crawford et al. (1991) that found structural constraint was more significant than any other constraints.

In terms of skill/confidence, virtual golf consumers may experience intrapersonal constraints (Mullin, Hardy, \& Sutton, 2014) derived from the common perception that golf is difficult to learn, as virtual golf necessitates physical movement and the same skillsets required in outdoor golf. While some consumers tend to perceive skill/confidence as a major constraint due to the involvement of physical activity and the difficulty of the sport in nature, physical activity does not necessarily constrain the existing golf consumers to participate in virtual golf because neither consumer of outdoor golf nor virtual golf expect the difficulty of the sport is reduced.

On the other hand, virtual golf consumers perceive time as one of the constraints to participation. Virtual golf enables consumers to take less time in total than the time taken for playing outdoor golf by saving time in preparation and transportation. However, virtual golf consumers may still have to spend quite a long time to complete a course and perceive it is too long to participate in. It would be interesting to see if virtual golf consumers feel differently when comparing to outdoor golf in terms of total time spent to complete a single golf course. Yet, the result of the study alerts practitioners to be aware of the time constraint, thus, they need to develop time-shortened virtual golf programs to keep the existing virtual golf consumers and to attract more new participants.

Lastly, it is noteworthy that cost was not a significant constraint for participation. Cost has been known as one of the significant constraints for participation in various leisure activities, particularly in golf industry in Republic of Korea. On the other hand, considering that reduced cost has been a major advantage to play virtual golf rather than outdoor golf, the result of this study confirmed that virtual golf industry has been effectively attracting people to participate in virtual golf.

In terms of the second research question (RQ2: How the negotiation process works in virtual golf?), results showed virtual golf participation had a negative relationship with constraints and a positive relationship with negotiation, supporting the hypotheses 1 (H1: Constraints have a negative direct influence on virtual golf participation.) and 3 (H3: Negotiation has a positive direct influence on virtual golf participation.). In addition, negotiation-efficacy had a positive relationship with negotiation and a negative relationship with constraints, which supported the hypotheses 4 (H4: Negotiation-efficacy has a positive direct influence on negotiation in virtual golf.) and 5 (H5: Negotiation-efficacy has a negative direct influence on constraints in virtual golf.). However, contrary to expectations, hypothesis 2 (H2: Constraints have a positive direct influence on negotiation in virtual golf.) was not supported, as constraints did not have a meaningful relationship with negotiation.

This result was opposed to the expectation that reduced constraints would positively influence participation through negotiation process. Regardless of negotiation effort, reduced constraints directly led to increased 
participation, thus, it has been confirmed that consumers decide to participate in virtual golf based on the existence or absence of leisure constraints. Therefore, this result was contrary to the finding of Jackson et al. (1993) that people are more likely to negotiate perceived leisure constraints when confronting one. The result of the current study indicated that perceived constraints have an impact on non-participation without negotiation. This does not necessarily implicate that those constraints are insurmountable to the consumers but highlights the importance of constraints to predict participation. To increase virtual golf participation, it is more important to eliminate each constraint than negotiate or overcome those perceived constraints. This result supported Dishman (1994) stating that more than half of participants last their sport activities no longer than six months and each individual's varying circumstantial constraints are the primary reasons to quit. Therefore, most importantly, this result suggests practitioners to find a way to eliminate or reduce constraints of skill/confidence and time to increase virtual golf participation.

\section{Conclusions}

This study provides a comprehensive understanding of interrelationships among leisure participation, constraints, and negotiation, particularly extending to the context of virtual golf. Especially, the findings of this study extend the existing knowledge on an individual's decision-making process in participating in leisure activities by confirming the difference between traditional leisure context and technology-based leisure activity. In other words, constraints are still a significant factor in decision-making process, and negotiation process is not a significant factor for virtual golf consumers' participation. Contrarily, the tendency of making decision in participating in virtual golf without negotiation process was identified.

Also, this study provides support for including negotiation-efficacy as a significant factor to examine an individual's participation and constraint to leisure activities, as Loucks-Atkinson and Mannell (2007) and White (2008) suggested the modification of seventh proposition of Jackson et al. (1993) that "The greater people's confidence in the successful use of negotiation resources to cope with constraints, the greater the motivations, the greater the effort to negotiate, the lesser the perception of constraints, and the higher the level of participation" (p. 356).

\section{Limitations and Directions for Future Research}

There are several limitations that ought to be improved in the future research in order to further develop the structural model of leisure constraints and negotiation in virtual golf. First, the sample was comprised of virtual golf participants in the Republic of Korea since it is the leading country of virtual golf. However, as numbers of virtual golf facilities in other countries/locations are growing, which allows golfers to have different experiences, it warrants identifying the relationship among constraints, negotiation, negotiation-efficacy, and participation of different target population (e.g., different nationalities, virtual golf participants only, and outdoor golf participants only) since diverse target population might share varying factors.

Second, gender of consumers in virtual golf is another realm that needs more investigation. A good amount of studies and statistics indicated the increased number of virtual golf participants in the Republic of Korea. However, women's participation in virtual golf has been fairly stagnating compared to men's participation, which is also consistent with the participation rate in outdoor golf. This gender-lopsided participation in virtual golf needs to be scrutinized based on our holistic understanding of leisure constraints structure and interrelationships among core variables we mentioned in this study. Especially, negotiation-efficacy might play a key role in explicating women's lack of participation in virtual golf.

Finally, future research should examine types of strategies people use to overcome perceived constraints. Our findings systematically demonstrated the interrelationships among constraints, negotiation effort, negotiationefficacy, and participation and successfully stretched into a new type of leisure. However, despite the emphasis 
on the role of negotiation efforts and negotiation-efficacy in virtual golf participation, the study design by nature did not allow to identify what consumers essentially do to deal with or overcome perceived constraints. Previous studies have suggested several negotiation strategies, which are rather broad and general (Jackson \& Rucks, 1995). Regarding specific conditions and unique characteristics of virtual golf, an extra effort needs to be made in order to appropriately comprehend negotiation strategies in virtual golf context. Specifically, qualitative approach would be helpful to explore negotiation strategies of virtual golf consumers, and it can be analyzed by considering three distinct levels of constraints including individual, interpersonal, and organizational factors.

\section{REFERENCES}

Alexandris, K., \& Carroll, B. (1997). Demographic differences in the perception of constraints on recreational sport participation: Results from a study in Greece. Leis. Stud.16(2), 107-125. DOI: https://doi.org/10.1080/026143697375449.

Browne, M. W., \& Cudeck, R. (1992). Alternative ways of assessing model fit. Soc. Methods Res. 21(2), 230-258. DOI: https://doi.org/10.1177/0049124192021002005.

Choi, C. (2016). An investigation of virtual golf in the Republic of Korea from a marketing perspective. Doctoral dissertation. Retrieved from Electronic Theses and Dissertations (Accession Order No. 2418).

Choi, C., Greenwell, T. C., Hums, M. A., \& Hambrick, M. E. (2019). Understanding consumer behaviors in virtual golf: Differences in leisure constraints. Sport Mark. Q.28, 46-57.

Crawford, D. W. \& Godbey, G. (1987). Reconceptualizing barriers to family leisure. Leis. Sci.9(2), 119-127. DOI: https://doi.org/10.1080/01490408709512151.

Crawford, D. W., Jackson, E. L., \& Godbey, G. (1991). A hierarchical model of leisure constraints. Leis. Sci.13(4), 309320. DOI: https://doi.org/10.1080/01490409109513147.

Dishman, R. K. (1994). Advances in Exercise Adherence. Champaign, IL: Human Kinetics.

Field, A. (2009). Discovering Statistics Using SPSS (3rd ed.). Thousand Oaks, CA: Sage Publications.

Han, H., Baek, H., Lee, K. \& Huh, B. (2014). Perceived benefits, attitude, image, desire, and intention in virtual golf leisure. J. Hosp. Market.Manag.23(5), 465-486. DOI: https://doi.org/10.1080/19368623.2013.813888.

Hawkins, B. A., Peng, J., Hsieh, C. M., \& Eklund, S. J. (1999). Leisure constraints: A replication and extension of construct development. Leis. Sci.21(3), 179-192. DOI: https://doi.org/10.1080/014904099273066.

Henderson, K. A., Bedini, L. A., Hecht, L. \& Schuler, R. (1995). Women with physical disabilities and the negotiation of leisure constraints. Leis. Stud.14(1), 17-31. DOI: https://doi.org/10.1080/02614369500390021.

Hooper, D., Coughlan, J., \& Mullen, M. R. (2008). Structural equation modelling: Guidelines for determining model fit. Electr. J. Bus. Res. Methods, 6(1), 53-60. DOI: https://doi.org/10.21427/D7CF7R.

Hu, L. T., \& Bentler, P. M. (1998). Fit indices in covariance structure modeling: Sensitivity to underparameterized model misspecification. Psychol. Methods, 3(4), 424-453. DOI: https://doi.org/10.1037/1082-989X.3.4.424.

Hubbard, J., \& Mannell, R. C. (2001). Testing competing models of the leisure constraint negotiation process in a corporate employee recreation setting. Leis. Sci. 23(3), 145-163. DOI: https://doi.org/10.1080/014904001316896846.

Iso-Ahola, S. E., \& Mannell, R. C. (1985). Social and psychological constraints on leisure. In M.G. Wade (Ed.), Constraints on leisure (pp. 111-151). Springfield, IL: Charles C. Thomas.

Jackson, E. L. (1988). Leisure constraints: A survey of past research. Leis. Sci. 10(3), 203-215. DOI: https://doi.org/10.1080/01490408809512190.

Jackson, E. L., Crawford, D. W., \& Godbey, G. (1993). Negotiation of leisure constraints. Leis. Sci.15(1), 1-11. DOI: https://doi.org/10.1080/01490409309513182.

Jackson, E. L., \& Dunn, E. (1991). Is constrained leisure an internally homogeneous concept? Leis. Sci.13(3), 167-184. DOI: https://doi.org/10.1080/01490409109513136.

Jackson, E. L. \& Rucks, V. C. (1993). Reasons for ceasing participation and barriers to participation: further examination of constrained leisure as an internally homogeneous concept. Leis. Sci.15(3), 217-230. DOI: https://doi.org/10.1080/01490409309513201.

Jun, J., \& Kyle, G. T. (2011). The effect of identity conflict/facilitation on the experience of constraints to leisure and constraint negotiation. J. Leis. Res.43(2), 176-204. DOI: https://doi.org/10.1080/00222216.2011.11950232. 
Jung, J., Park, H., Kang, H., Lee, S., \& Hahn, M. (2010). Measurement of initial motion of a flying golf ball with multiexposure images for screen-golf. IEEE Trans. Consum. Electr.56(2), 516-523. DOI: https://doi.org/10.1109/TCE.2010.5505964.

Kerr-Dineen, L. (2018). This is a simulation. (And it's still golf!). Retrieved September 21, 2017, from https://www.golfdigest.com/story/this-is-a-simulation-and-its-still-golf-golf-simulators

Kim, T., Seo, H., Kim, M. C., \& Chang, K. (2014). Customer productivity in technology-based self-service of virtual golf simulators. Int. J. Sports Mark. Sponsorship, 16(1), 24-39. DOI: https://doi.org/10.1108/IJSMS-16-01-2014-B003.

Lee, D., Cheon, W., Judge, L. W., Shin, H., \& Kim, K. (2012). Motives and marketing stimuli affecting eSports consumption: Cross-cultural perspectives. Int. J. SportsManag. 13, $203-223$.

Lee, H., Chung, S., \& Lee, W. (2013). Presence in virtual golf simulators: The effects of presence on perceived enjoyment, perceived value, and behavioral intention. New Media Soc. 15(6), 930-946. DOI: https://doi.org/10.1177/1461444812464033.

Loucks-Atkinson, A., \& Mannell, R. C. (2007). Role of self-efficacy in the constraints negotiation process: The case of individuals with fibromyalgia syndrome. Leis. Sci. 29(1), 19-36. DOI: https://doi.org/10.1080/01490400600983313.

Lyu, S. O., \& Lee, Y. (2018). How do golf tourists manage golfing constraints? A choice modeling approach. J. Hosp. Tour. Res. 42(2), 295-318. DOI: https://doi.org/10.1177/1096348015597036.

Mullin, B. J., Hardy, S., \& Sutton, W. A. (2014). Sport Marketing. Champaign, IL: Human Kinetics.

Nunnally, J.C ., \& Bernstein, I. H. (1994). Psychometric Theory (3rd ed.). New York, NY: McGraw-Hill Education.

Ridinger, L.L., Funk, D. C., Jordan, J. S., \& Kaplanidou, K. K. (2012). Marathons for the masses: exploring the role of negotiation-efficacy and involvement on running commitment. J. Leis. Res., 44(2), 155-178. DOI: https://doi.org/10.1080/00222216.2012.11950260.

Schupak, A. (2018). Simulated golf, real results: Off-course participation helps drive engagement. Retrieved November 13, 2017, from https://www.thengfq.com/2018/01/simulated-golf-real-results-off-course-participation-helps-driveengagement/

Scott, D. (1991). The problematic nature of participation in contract bridge: A qualitative study of group-related constraints. Leis. Sci.13(4), 321-336. DOI: https://doi.org/10.1080/01490409109513148.

Smith, R. W. (1987). Leisure of disable tourists: Barriers to participation. Annals Tour. Res. 14(3), 376-389. DOI: https://doi.org/10.1016/0160-7383(87)90109-5.

Stevens, J. P. (2009). Applied Multivariate Statistics for the Social Sciences (5th ed.). New York, NY: Routledge/Taylor \& Francis Group.

Um, S., \& Crompton, J.L. (1992). The roles of perceived inhibitors and facilitators in pleasure travel destination decisions. J. Travel Res. 30(3), 18-25. DOI: https://doi.org/10.1177/004728759203000303.

White, D.D. (2008). A structural model of leisure constraints negotiation in outdoor recreation. Leis. Sci. 30(4), 342-359. DOI: https://doi.org/10.1080/01490400802165131.

Young, I.S., \& Pedersen, P.M. (2010). Participants' service quality perceptions of fantasy sports 116 websites: The relationship between service quality, customer satisfaction, attitude, and actual usage. Sport Mark. Q. 19(2), 78-87.

\section{AUTHOR'S ADDRESS:}

\section{Chulhwan Choi}

Department of Golf Industry

College of Physical Education, Kyung Hee University

Seocheon-dong 1, Giheung-gu, Yongin-si,

Gyeonggi-do 17104, Korea

E-mail: chulhwanchoi@yahoo.com

Received: 10 May 2019; Accepted: 28 November 2019 